j. port. sci. res.
ISSN: 2616-7441 (Online)
ISSN: 2616-6232 (Print)
ISN 2616-7220 (USB)

\title{
New Perceptions in the Cardioprotective Effect of Metformin Against Isoproterenol Induced Cardiotoxicity in Male Rats
}

\author{
Yahya Al-Qaisy*1, I. S. Arif ${ }^{2}$, M. Ibraheem ${ }^{3}$ \\ $1 \& 2$ College of Pharmacy, Uruk University, Baghdad. Iraq. \\ ${ }^{3}$ College of Medicine, Mustansyria University. Baghdad. Iraq.
}

yahya.gh.alqaisy@gmail.com

\begin{abstract}
Background and objective: Recent clinical trials have shown that metformin improves clinical cardiovascular outcome in type-2 diabetic patients independently of its insulin-sensitizing effect. This study was sought to evaluate the potential cardioprotective effects of metformin on isoproterenol-induced cardiac stress in diabetic and non-diabetic rats. Materials and Methods: Diabetes was induced by using streptozocin $(60 \mathrm{mg} / \mathrm{kg}$, i.p.) while non-diabetic rats received saline. Rats in both experimental groups were then randomized to receive different doses of metformin $(75,150,300 \mathrm{mg} / \mathrm{kg}$ i.p.) for 6 weeks. Cardiac stress was induced by isoproterenol $(150 \mathrm{mg} / \mathrm{kg}$ i.p.) for two successive days. Specific biomarkers of tissue injury, namely brain natriuretic peptide (BNP), cardiac troponin-T (cTn-T), matrix metalloproteinase (MMP), tissue necrotic factor- $\alpha$ (TNF), were assessed. Data were analysed using one-way ANOVA followed by Newman Keuls post hoc test Results: The results showed that metformin significantly limited isoproterenolinduced myocardial injury in both diabetic and non-diabetic rats. Metformin significantly decreased the elevated serum levels of brain natriuretic peptide (BNP), matrix metalloproteinase (MMP), cardiac troponin $\mathrm{t}(\mathrm{cTn}-\mathrm{T})$ which was induced by isoproterenol. It also limited expression of tissue necrotic factor- $\alpha$ (TNF$\alpha$ ) following the cardiac injury in diabetic and non-diabetic rats.
\end{abstract}

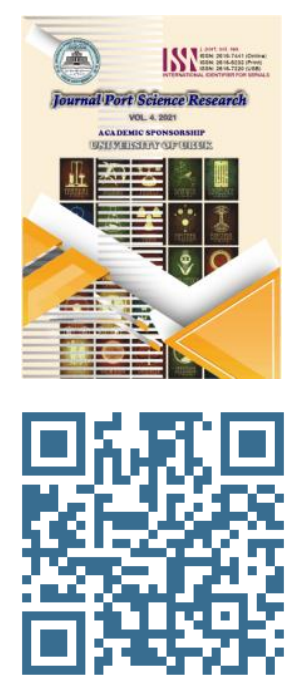

Crossref

$10.36371 /$ port.2021.6

Keywords: Metformin, Type 2 diabetes mellitus, cardio-protection, Isoproterenol-induced cardiac stress, Brain natriuretic peptide, Matrix metalloproteinase, cardiac troponin type T, Tumour necrotic factor- $\alpha$.

\section{INTRODUCTION}

Metformin is one of the most prescribed anti-hyperglycaemic drugs used to control blood glucose level in type-2 diabetic patients. In addition to that, it has been reported that the therapeutic applications of metformin could not be limited to control diabetes but could also have some beneficial cardioprotection effects1,2. Clinically, it has been reported that metformin has a direct cardioprotection effects and reduces the mortality rate in diabetic patients independently of its' glycaemic control effect3,4. Several mechanisms of action by which metformin might induce its cardio-protection have been suggested including activation of 5'-adenosine monophosphate-activated protein kinase (AMPK)5,6. Salt's laboratory demonstrated that activation of AMPK with 5'aminoimidazole-4-carboxamide ribonucleoside enhanced the phosphorylation of endothelial nitric oxide synthase (eNOS) at its activation site (Ser1177) in a dose dependent manner in human aortic endothelial cells7.

It has also been demonstrated that metformin improved cellular antioxidant gene expression to mitigate cardiac remodelling following myocardial infarction8. Like wise, it has been reported that metformin attenuated the expression of collagen following myocardial infaction9.Moreover, there is an increasing body of evidence suggests that metformin therapy has anti-atherogenic activity via suppressing the expression of endothelial adhesion molecules in in vitro and in vivo studies 10 .

Clinically, metformin is shown to enhance endotheliumdependent microvascular blood flow and improve symptoms of myocardial infarction (MI) presented by $38 \%$ decrease in maximal ST-segment depression and 30\% decrease in the occurrence of chest pain11. Additionally, it has been shown that metformin treatment improved deteriorated lipid profile in type-2 diabetic patients 12 .

Interestingly, metformin treatment effectively improved cardiac contractility and remodeling in ischemia-induced heart failure model in rat9.

The field of cardio-protection has failed so far to introduce a drug which can prevent cardiac injury that occur during acute myocardial infarction, despite the extensive efforts over the last two decades.

There are many reasons for this failure which have been discussed in more details in recent review papers 13,14 . One 


\section{$0,0.0 \cdot 0 \cdot 0 \cdot 0 \cdot 0 \cdot 0$

of the most important reasons probably is that the experimental model, which is employed to characterize the cardio-protection of the drug under investigation, does not reflect the clinical situation of patients with ischemia heat disease.

Majority of those patients often have other comorbidities such as diabetes and hypocholesteremia, heart failure and age13. Therefore, this complexity needs to be taken into consideration when designing experimental cardioprotection studies.

This study investigated the potential cardioprotective effects of metformin against cardiac injury in diabetic and nondiabetic rats. This study hypothesized that metformin can limit myocardial injury in the presence and absence of diabetes as a comorbidly using a rat model of isoproterenolinduced cardiac injury in vivo.

\section{MATERIALS AND METHODS}

\section{Animals}

Male Wister rats weighted $120-180 \mathrm{~g}$ was used in this study. Rats were housed with free excess to water and small rodent's food at a constant temperature $\left(20^{\circ} \mathrm{C}-25^{\circ} \mathrm{C}\right)$ and humidity for 10 days before any experimentation in a $12 \mathrm{hr}$ light/dark cycle in the Animals Facility at Al-Mustansiriyah College of Pharmacy. All experimental protocols were carried out at the laboratories of post-graduate students/college of pharmacy/ Almustansiriyah university (May 2016 - Dec. 2016) to All handling and procedures were approved by the Animals Welfare Committee in the College of Pharmacy, AlMustansiriyah University.

\section{Induction of diabetes}

Streptozocin (STZ) was freshly prepared and administered $(60 \mathrm{mg} / \mathrm{kg}$, i.p.) as a single dose. Fasting blood sugar (FBS) level was monitored (using ONETOUCH glucometer) for 10 days and only the rats with FBS $>250 \mathrm{~g} / \mathrm{dl}$ were considered as diabetic and included in the study.

\section{Induction of cardiac stress:}

Isoproterenol (ISO) solution was prepared freshly, and rats received ISO (150 mg/kg, i.p.) for two days to induce cardiac stress .

\section{Experimental design}

Male Waster rats were randomized into two main groups: diabetic and non-diabetic group. Rats in the diabetic group received STZ (60 mg/kg, i.p.) as a single dose to induce diabetes while non-diabetic rats received saline. The whole experimental protocol is shown in (Figure 1).

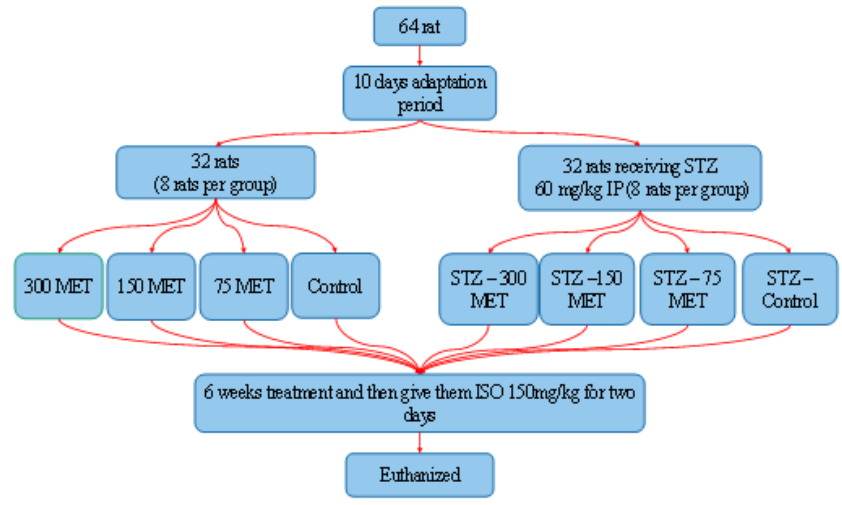

Figure 1: Schematic diagram showing the experiment protocols to induced diabetes and cardiac injury.

\section{Materials and chemicals}

Streptozocin and isoproterenol are purchased from SigmaAldrich, Gillingham, UK, Metformin was sourced from Pioneer Pharmaceutical Company, Sulaymaniya, Iraq. ELISA kits for (BNP, MMP-1, cTn-T) were purchased from Shanghai YeHua Biological Technology, Shanghai, China. Immunohistochemistry kit for TNF- $\alpha$ (MaxTagTM Histo IHC Kit) was purchased from (Rockland-inc, USA) .

\section{Samples collection}

Blood sample was collected from the left ventricle by heart puncture technique after anesthetized the rats with diethyl ether. Blood sample was centrifuged with 3000rpm for 6 mins and the serum was recovered and stored at $-20{ }^{\circ} \mathrm{C}$ until required.

\section{Tissue sampling and processing}

The heart was harvested immediately after collecting the blood sample and washed with saline to remove any blood residue. The heartwas then fixed with $10 \%$ formalin $(\mathrm{pH} 7.4)$ for an hour then incubated with an increasing level of ethanol (50\%, 70\%, 80\%, 90\% then 100\%). The heart was then embedded in paraffin then sectioned using microtome into (4 $\mu \mathrm{M})$ sections. Heart sections were placed on microscope slides and fixed with $4 \%$ formaldehyde for 30 minutes. Slides were then treated, according to the manufacturer's instruction, with TNF- $\alpha$ kit (MaxTag ${ }^{\mathrm{TM}}$ Histo IHC Kit, Rockland-inc, USA) .

\section{Photography \& immunohistochemically staining analysis of sections}

Aperio positive pixel count algorithms program from Aperio image scope software v12.1.0.5029 (Aperio Technologies Inc, USA) used for digital heart slides analysis. These algorithms allow to quantifyTNF- $\alpha$ marker within the sections to automatically calculate the prevalence of TNF- $\alpha$ in each section. This programme calculates the number of 
pixels which have stained with the kit's dye and calculate the average intensity of staining for that dye across the tissue section.

\section{Statistical analysis}

Data were presented as mean \pm SEM and analysed by oneway ANOVA followed by Newman Keuls post-hoc test using GraphPad Prism® software (2007, version 5.01, USA). At p value $<0.05$, differences considered as significant

\section{RESULTS}

\section{Effect of metformin on serum BNP level}

Isoproterenol induced a significant increase $\quad(p<0.05$ compared with saline treated rats) in the serum level of BNP.

In diabetic rats, metformin $(75,150$ and $300 \mathrm{mg} / \mathrm{kg})$ significantly attenuated $(\mathrm{p}<0.05)$ isoproterenol-induced elevated BNP level by $(16 \%, 26 \%$, and $41 \%$, respectively) compared to the vehicle group (Figure 2).

Similarly, metformin treatment (150 and $300 \mathrm{mg} / \mathrm{kg})$ effectively protected non-diabetic heart as evidence of the mitigated level of $\mathrm{BNP}(\mathrm{p}<0.05)$ by $(21 \%, 36 \%$ respectively) compared to the control (Figure 3 ).

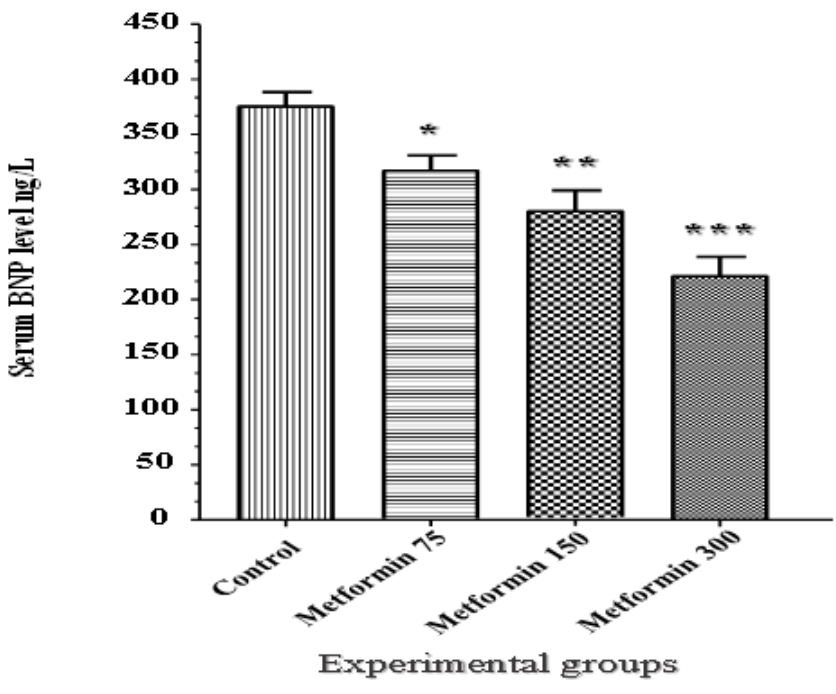

Figure 2: Serum brain natriuretic peptide (BNP) levels for diabetic groups. Data were analysed using one-way ANOVA followed by

Newman Keuls post hoc test and reported as mean \pm SEM. $*_{p}<0.05, * * p<0.01, * * * p<0.001$ vs control (saline). Rats treated with Metformin 75, 150 , and $300 \mathrm{mg} / \mathrm{kg} / 24 \mathrm{hrs} \mathrm{i.p.}(n=8)$. Data expressed as a Mean \pm SEM.

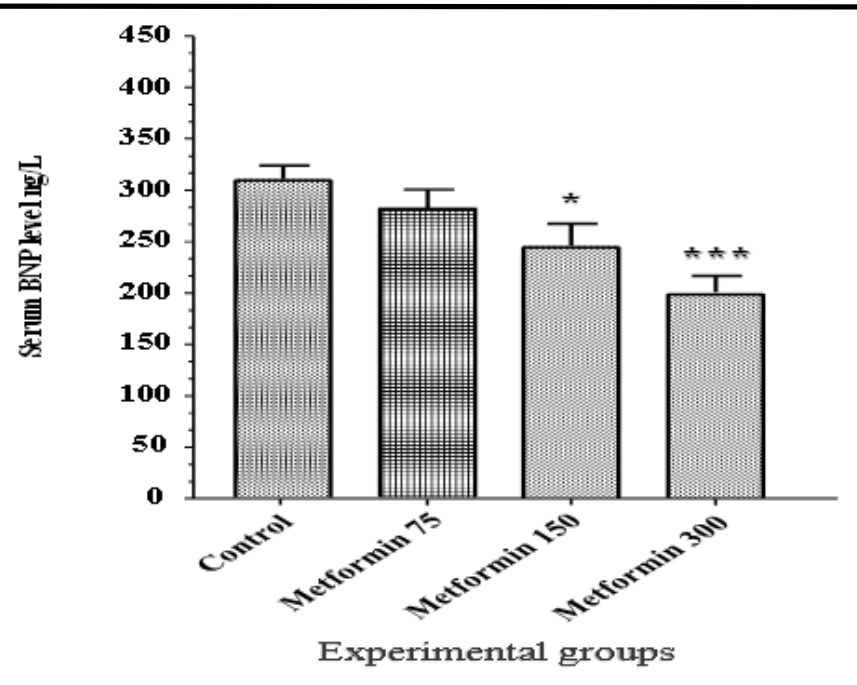

Figure 3: Serum brain natriuretic peptide (BNP) levels for nondiabetic groups. Data were analysed using one-way ANOVA followed by Newman Keuls post hoc test and reported as mean \pm SEM. *p<0.05, ***p<0.001 vs control (saline).Rats treated with Metformin 75, 150, and $300 \mathrm{mg} / \mathrm{kg} / 24 \mathrm{hrs} \mathrm{i.p.}(n=8)$. Data expressed as a Mean \pm SEM.

\section{Effect of metformin on serum MMPs-1 level}

In diabetic groups, all three dosing schedules of metformin $(75,150$, and $300 \mathrm{mg} / \mathrm{kg} /$ day) suppressed the elevated level of MMP-1 post isoproterenol administration significantly $(\mathrm{p}<0.05)$ by $(16 \%, 29 \%$, and $40 \%$ respectively) compared to saline-treated group (Figure 4). In the absence of diabetes, metformin treatment at ( 150 and $300 \mathrm{mg} / \mathrm{kg} /$ day) for 6 weeks prior to isoproterenol-induced myocardial infarction significantly abrogated the elevated level of MMP-1 $(\mathrm{p}<0.05)$ by (22\% and $30 \%$ respectively) compared to control group $(19.83 \pm 0.717 \mathrm{ng} / \mathrm{L}, \quad \mathrm{p}<0.001, \quad$ Figure 5).

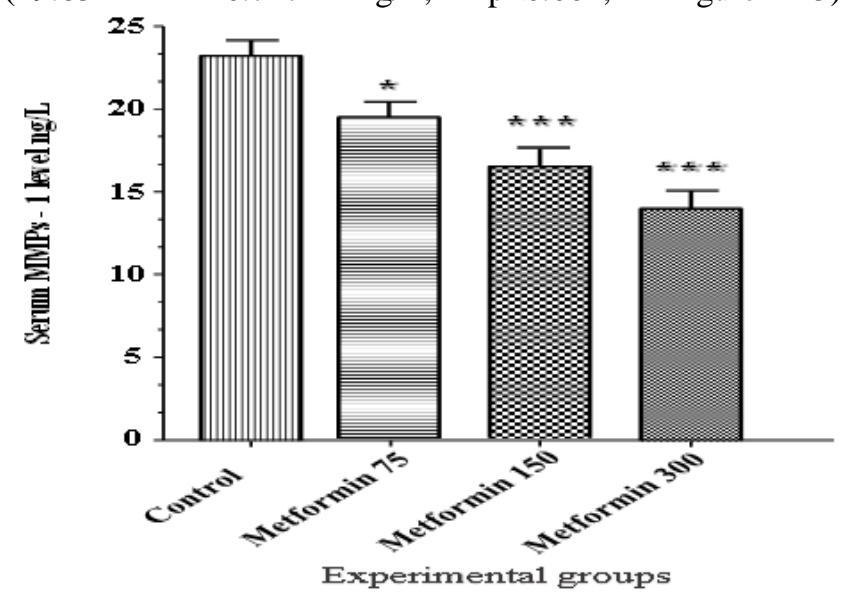

Fig 4 Serum matrix metalloproteinase-1 (MMP-1) levels for diabetic groups. Data were analysed using one-way ANOVA followed by Newman Keuls post hoc test and reported as mean \pm SEM. *p<0.05, ***p<0.001 vs control (saline).Rats treated with

Metformin 75, 150, and $300 \mathrm{mg} / \mathrm{kg} / 24 \mathrm{hrs} \mathrm{i.p.}(n=8)$. Data expressed as a Mean \pm SEM. 


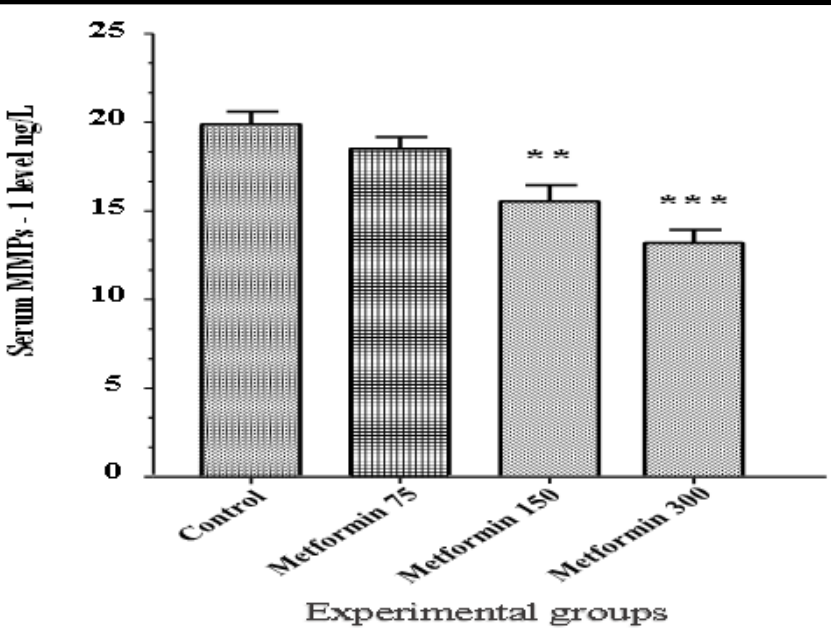

Fig 5 Serum matrix metalloproteinase-1 (MMP-1) levels for nondiabetic groups. Data were analysed using one-way ANOVA followed by Newman Keuls post hoc test and reported as mean \pm SEM. $* * p<0.01, * * * p<0.001$ vs control (saline).Rats treated with

Metformin 75, 150, and $300 \mathrm{mg} / \mathrm{kg} / 24 \mathrm{hrs} \mathrm{i.p.}(n=8)$. Data expressed as a Mean \pm SEM.

\section{Effect of metformin on serum cTn-T level}

Metformin treatment protected the heart against isoproterenol by abrogated the elevated level of cTn-T in diabetic rat in a dose dependent manner with maximum protection at 300 $\mathrm{mg} / \mathrm{kg} /$ day compared to vehicle-treated diabetic rat $(\mathrm{p}<0.001$, Figure 6). Similarly, metformin therapy (150 and 300 $\mathrm{mg} / \mathrm{kg} /$ day) for 6 weeks before isoproterenol attenuated level of serum cTn-T significantly $(\mathrm{p}<0.05)$ by $(23 \%$ and $36 \%$, respectively) compared to control group in normoglycemic rats (Figure 7 ).

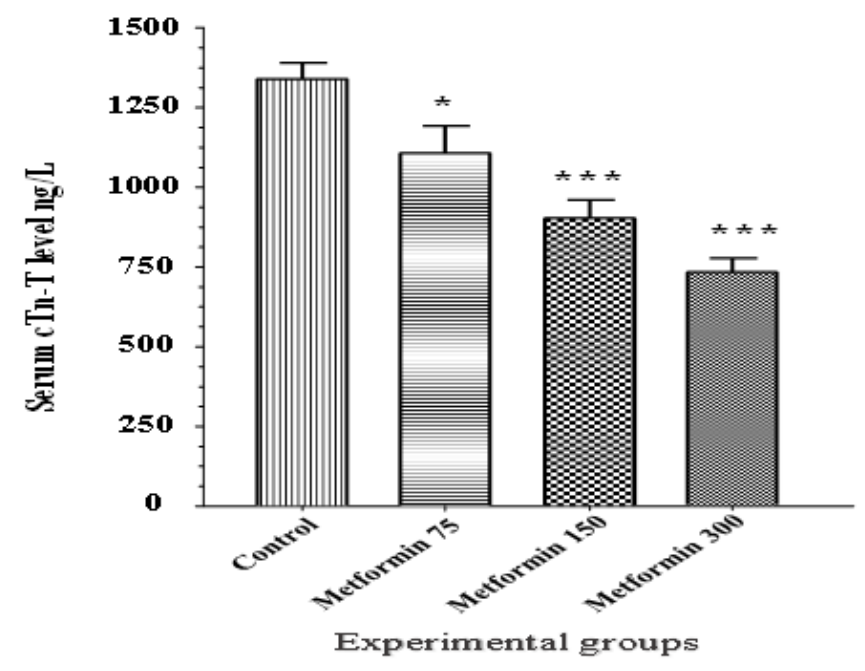

Fig 6 Serum cardiac troponin-T(cTn-T) levels for diabetic groups. Data were analysed using one-way ANOVA followed by Newman

Keuls post hoc test and reported as mean \pm SEM. *p<0.05,

$* * * p<0.001$ vs control (saline).Rats treated with Metformin 75,

150 , and $300 \mathrm{mg} / \mathrm{kg} / 24 \mathrm{hrs} \mathrm{i.p.}(n=8)$. Data expressed as a Mean \pm SEM.

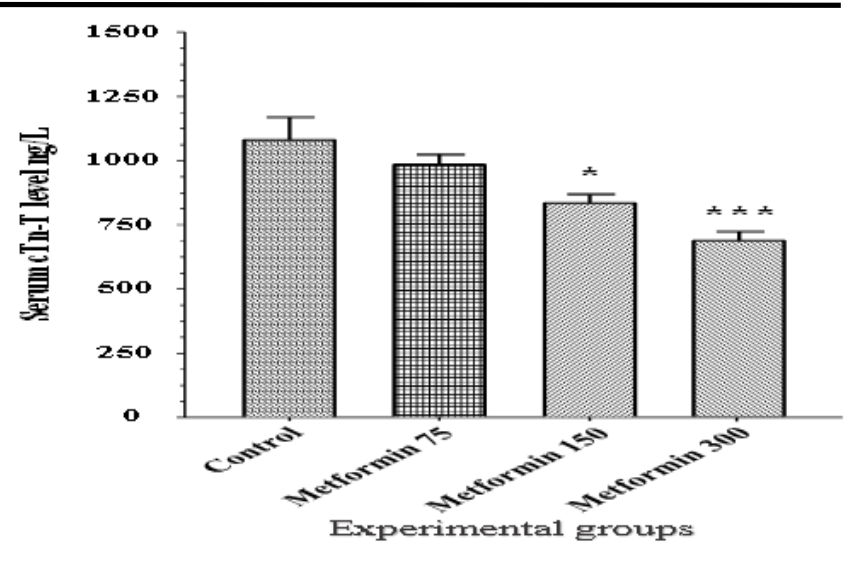

Fig 7 Serum cardiac troponin-T(cTn-T) levels for non-diabetic groups. Data were analysed using one-way ANOVA followed by

Newman Keuls post hoc test and reported as mean \pm SEM. $* p<0.05, * * * p<0.001$ vs control (saline).Rats treated with Metformin 75, 150, and $300 \mathrm{mg} / \mathrm{kg} / 24 \mathrm{hrs} \mathrm{i.p.}(n=8)$. Data expressed as a Mean \pm SEM.

Effect of metformin treatment on the expression of TNF$\boldsymbol{\alpha}$

TNF- $\alpha$ is a potent pro-inflammatory mediator and can trigger different forms of cytokines and inflammatory mediators. Metformin (150 and $300 \mathrm{mg} / \mathrm{kg}$ ) significantly supressed the expression of TNF- $\alpha$ in cardiac tissue $(\mathrm{p}<0.05)$ by $(63 \%$, and $84 \%$, respectively) compared with vehicle-treated diabetic rats (Figure 8).

In non-diabetic groups, metformin with doses (150 and 300 $\mathrm{mg} / \mathrm{kg}$ ) supressed the expression of TNF- $\alpha$ in cardiac tissue significantly $(\mathrm{p}<0.05)$ by $(64 \%$ and $83 \%$, respectively) compared with the control group (Figure 9).

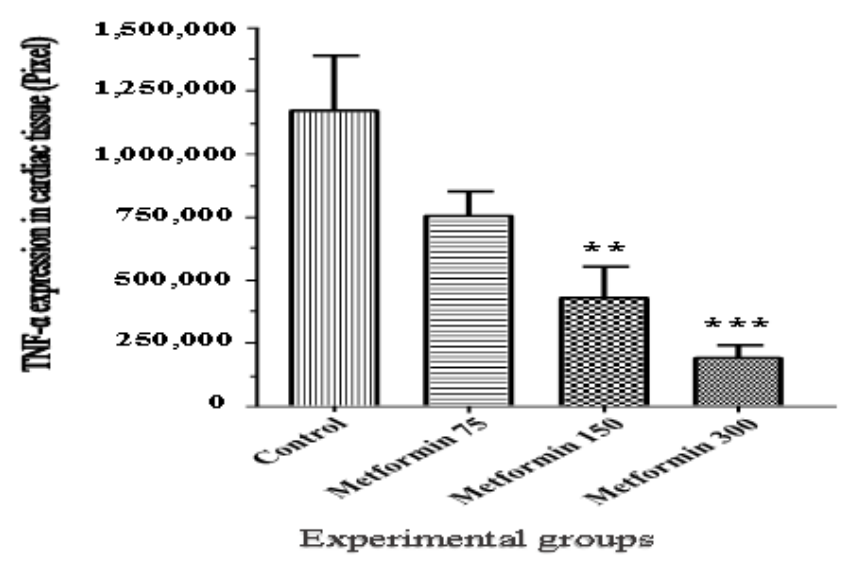

Figure 8: Tumour necrotic factor- $\alpha$ expression in cardiac tissue in groups of diabetic rats. Data were analysed using one-way ANOVA followed by Newman Keuls post hoc test and reported as mean \pm SEM. $* * p<0.01, * * * p<0.001$ vs control (saline). Rats treated with Metformin 75, 150 , and $300 \mathrm{mg} / \mathrm{kg} / 24 \mathrm{hrs} \mathrm{i.p.}(n=8)$. Data expressed as a Mean \pm SEM 


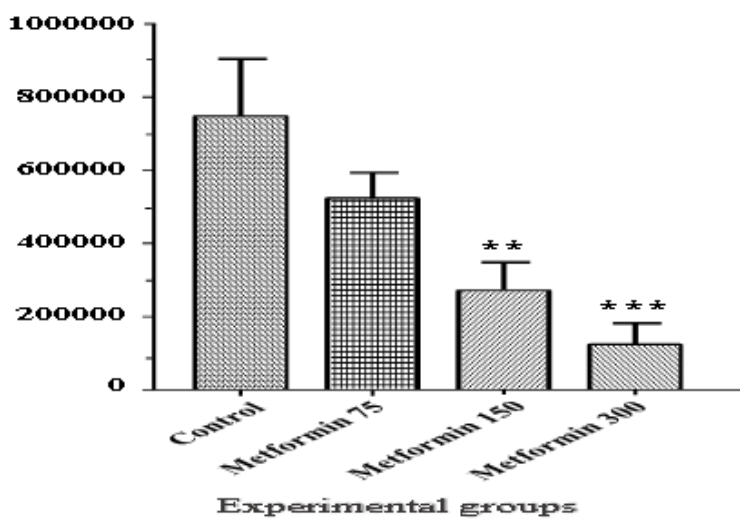

Figure 9: Tumour necrotic factor- $\alpha$ expression in cardiac tissue in groups of non-diabetic rats. Data were analysed using one-way ANOVA followed by Newman Keuls post hoc test and reported as mean \pm SEM. $* * p<0.01, * * * p<0.001$ vs control (saline).Rats treated with Metformin 75, 150, and $300 \mathrm{mg} / \mathrm{kg} / 24 \mathrm{hrs}$ i.p. $(n=8)$. Data expressed as a Mean \pm SEM.

This study shows for the first time a head-to-head comparison for the cardioprotective of metformin against isoproterenolinduced myocardial infarction diabetic and non-diabetic rats in vivo .

The finding support that hypothesis that metformin has cardioprotective activities and it is signalling through a mechanism which is functioning in the presence comorbidies such as type- 2 diabetes mellitus.

Catecholamine, in general, may go through auto-oxidation pathway which result in the modulation of oxidative products and generation of oxygen reactive species (ROS). The ROS is one of the main determines to the outcome of myocardial infarction. Those oxidative products are believed to be responsible for myocardial damage, however, the exact mechanism by which isoproterenol induces myocardial infarction and cardiomyopathy is still under investigation and yet to be defined. It has been suggested that isoproterenol could induce imbalance between oxygen demand and supply because of the enhanced myocardial activity15. Accordingly, the energy depletionthuscan cause a cascade of biochemical and structural changes leads to myocardial cell damage. The use of isoproterenol-induced myocardial infarction is considered as a relatively easy technique, reproducible and required only a short time to induce myocardial infarction compared to coronary occlusion technique16.

The BNP is a neuro-hormone, released mainly from the left ventricle which plays an important role in the regulation of body fluids and blood pressure and it is an early indicator for acute and chronic heart

failure 17.The level of BNPusually increases when there is a stress or abnormality in the heart chamber or in volume overload. Drugs that inhibit the level of BNP have a

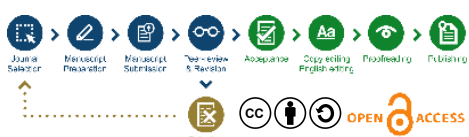

cardioprotective effect as its reflect the positive drug effect on the left ventricle, MI, HF18.In diabetic patients, BNP level was elevated as aresult of volume expansion and fluid overload while glycaemic control led to a significant decrease in the BNP level19. Isoproterenol causedendoplasmic reticulum (ER) stress and elevation of BNP level through AMPK inhibition compared with normal non-treated rats16.It has been reported that metformin exerted its cardioprotective effects through activation of AMPK, inhibition of ER stress and attenuation of elevated BNP level. In line,metformin treatment for 4 weeks $(100 \mathrm{mg} / \mathrm{kg} / 24 \mathrm{hr})$ produced a significant reduction $(\mathrm{p}<0.05)$ in the BNP level compared with non-treated rats16. Furthermore, metformin could also signal via enhancing the activating of other cardioprotective kinases. For example, metformin elicited its cardioprotection through enhancing the phosphorylation of eNOS at Ser1177 and upregulated eNOS mRNA expression. Nitric oxide mediatescrucial physiological actions, including inhibition of oxidative stress, platelet aggregation, vasodilation, leucocyte chemotaxis and apoptosis, which make it a potent cardioprotective signalling molecule20.Clinically, it has recently been shown by Hamasaki and colleagues that metformin treatment for 90 days significantly mitigated the level of BNP in type-2 diabetic patients21. Likewise, four months treatment with metformin significantly reduced the BNP level in heart failure patients compared to placebotreated patients 21 . These findings are in line with the above resultsshowing thatmetformin can protect the heart against cardiac injury in the presence and absence of diabetes mellitus.

MMP-1 is a protease which is involved in tissue remodelling in physiological and pathological conditions. In cardiac pathology, there is an imbalance between tissue-derived inhibitor of metalloproteinase (TIMP) and MMP which leads to excessive activation of MMP. Elevated level of MMP-1 then stimulateabnormal cardiac extracellular matrix (cECM) expression, leading to vascular and cardiac abnormities 18 . Recent studies showed that MMP-1 activity was up-regulated in cardiac tissues by $\beta$-adrenergic stimulation in vivo. These results using a MMP inhibitor suggest that both MMPs may participate in the myocyte hypertrophy induced by $\beta$ adrenergic stimulation through the IGF axis22. The MMP plays an important role in the myocardial dysfunction following ischaemia/reperfusion injury in rat18. The early increase in MMP activity produces a proteolytic environment that may contribute to myocardial stunning injury in humans23. Metformin exerts a cardioprotective effect through influencing PKC-dependent activation of MMP-1 by inhibition of ERK1/2/NF-kappaB pathway in human aortic smooth muscle cell24. In addition, the glycaemic control achieved by metformin in diabetic rats is reported to protect the vasculature against hyperglycaemia-induced insults and 
mitigate vascular remodelling25. Metformin treatment (150 $\mathrm{mg} / \mathrm{kg} / 24 \mathrm{hr}$ ) significantly reduced the level of MMPs in isoproterenol-induced cardiac hypertrophy inmice26. Moreover, it has been reported that metformin treatment (300 $\mathrm{mg} / \mathrm{kg}$ ) for 4 weeks produced a significant reduction in MMP activity in insulin-resistant rats compared withnon-treated rats27. The results of this study are in line with others and show that metformin treatment for 6 weeks produced a dose dependant suppression in the serum MMP-1 level in both diabetic and non-diabetic rats.

Cardiac Tn-T is a tissue specific biomarker for myocardial injury and extensively used clinically. It has been demonstrated that a bolus dose of metformin $(125 \mu \mathrm{g} / \mathrm{kg})$ before ischaemia or at reperfusion significantly reduced myocardial injury and limited cTn-T level following myocardial ischaemia/reperfusion injury in nondiabetic and diabetic mice8.Chronic use of metformin in diabetic patient with ST-segment elevation myocardial infarction exhibited a significant attenuation in cTn-T level compared with nontreated patients 28. Furthermore, metformin abrogated the elevated level of cTn-T induced in isoproterenol-induced myocardial infarction in rat29. Taken together, the results of this study are consistent with others and demonstrated that metformin treatment produced a dose dependence suppression in the elevated level of cTn-T in both diabetic and non-diabetic rats .

TNF- $\alpha$ is a pro-inflammatory cytokine, produced from nucleated cells in the heart. The level of TNF- $\alpha$ is elevated in case of heart failure. The inflammatory response following an ischaemic event in the heart triggers innate stress kinases and cytokines which exacerbate the cardiac damage and affect deteriorate cardiac contractility 30 . Using Human umbilical vein endothelial cells, it has been reported that a unique antiinflammatory effect of metformin when it reversed the deleterious effects of TNF- $\alpha$ via PI3K/AMPK dependent signalling mechanism31. Chronic treatment with metformin significantly protected the heart and suppressed the level of TNF- $\alpha$ in metformin-treated rats32,34. Moreover, it has also been shown that metformin treatment suppressed the TNF- $\alpha$ through activation of AMPK in rats35,36. Furthermore, acute and chronic treatment with metformin exerted a dose dependant reduction in TNF- $\alpha$ through activation of AMPK37,38.Together, the data of this study are showing that metformin possesses a considerable anti-inflammatory effect which could have a significant clinical implication in diabetes and other pathologies.

\section{CONCLUSION}

The principle findings of this study are; metformin treatment limited myocardial infarction when it was given before cardiac injury, and, the cardioprotective mechanism of action of metformin functions in the presence and absence of diabetes mellitus.

This study provides convincible evidence that metformin has cardioprotective effect which can potentially protect the heart against myocardial infarction and improve the clinical outcome. Cardioprotection established by metformin mitigated tissue injury biomarkers following isoproterenol in non-diabetic and diabetic rats. Characterisation of the signalling pathway by which metformin mediates its cardioprotective could be an interesting topic for future investigation.

\section{REFERENCES}

[1] Abbasi, F., Chu, J. W., McLaughlin, T., Lamendola, C., Leary, E. T., \& Reaven, G. M. (2004). Effect of Metformin Treatment on Multiple Cardiovascular Disease Risk Factors in Patients with Type 2 Diabetes Mellitus. Metabolism: Clinical and Experimental, 53(2), 159-164. https://doi.org/10.1016/j.metabol.2003.07.020

[2] Lainscak, M., von Haehling, S., Springer, J., \& Anker, S. D. (2007). Biomarkers for chronic heart failure. Heart Failure Monitor. https://doi.org/10.1007/s00059-009-3316-4

[3] Apaijai, N., Chinda, K., Palee, S., Chattipakorn, S., \& Chattipakorn, N. (2014). Combined vildagliptin and metformin exert better cardioprotection than monotherapy against ischemia-reperfusion injury in obese-insulin resistant rats. $P L O S$ ONE, 9(7). https://doi.org/10.1371/journal.pone.0102374

[4] Bell, R. M., Bøtker, H. E., Carr, R. D., Davidson, S. M., Downey, J. M., Dutka, D. P., ... Yellon, D. M. (2016, July 1). 9th Hatter Biannual Meeting: position document on ischaemia/reperfusion injury, conditioning and the ten commandments of cardioprotection. Basic Research in Cardiology. Dr. Dietrich Steinkopff Verlag GmbH and Co. KG. https://doi.org/10.1007/s00395-016-0558-1

[5] Bulluck, H., Yellon, D. M., \& Hausenloy, D. J. (2016, March 1). Reducing myocardial infarct size: Challenges and future opportunities. Heart. BMJ Publishing Group. https://doi.org/10.1136/heartjnl-2015-307855 
[6] Calvert, J. W., Gundewar, S., Jha, S., Greer, J. J. M., Bestermann, W. H., Tian, R., \& Lefer, D. J. (2008). Acute metformin therapy confers cardioprotection against myocardial infarction via AMPK-eNOS- mediated signaling. Diabetes, 57(3), 696-705. https://doi.org/10.2337/db07-1098

[7] Calvert, J. W., Gundewar, S., Jha, S., Greer, J. J. M., Bestermann, W. H., Tian, R., \& Lefer, D. J. (2008). Acute metformin therapy confers cardioprotection against myocardial infarction via AMPK-eNOS- mediated signaling. Diabetes, 57(3), 696-705. https://doi.org/10.2337/db07-1098

[8] Cha, H. N., Choi, J. H., Kim, Y. W., Kim, J. Y., Ahn, M. W., \& Park, S. Y. (2010). Metformin inhibits isoproterenol-induced cardiac hypertrophy in mice. Korean Journal of Physiology and Pharmacology, 14(6), 377-384. https://doi.org/10.4196/kjpp.2010.14.6.377

[9] Dal, K., Ata, N., Yavuz, B., Sen, O., Deveci, O. S., Aksoz, Z., ... Ertugrul, D. T. (2014). The relationship between glycemic control and BNP levels in diabetic patients. Cardiology Journal, 21(3), 252-256. https://doi.org/10.5603/cj.a2013.0109

[10] Davis, B. J., Xie, Z., Viollet, B., \& Zou, M. H. (2006). Activation of the AMP-activated kinase by antidiabetes drug metformin stimulates nitric oxide synthesis in vivo by promoting the association of heat shock protein 90 and endothelial nitric oxide synthase. Diabetes, 55(2), 496-505. https://doi.org/10.2337/diabetes.55.02.06.db05-1064

[11] Derbali, A., Mnafgui, K., Affes, M., Derbali, F., Hajji, R., Gharsallah, N., ... El Feki, A. (2015). Cardioprotective effect of linseed oil against isoproterenol-induced myocardial infarction in Wistar rats: a biochemical and electrocardiographic study. Journal of Physiology and Biochemistry, 71(2), 281-288. https://doi.org/10.1007/s13105-015-0411-2

[12] Goldberg, R., Temprosa, M., Otvos, J., Brunzell, J., Marcovina, S., Mather, K., ... Barrett-Connor, E. (2013). Lifestyle and metformin treatment favorably influence lipoprotein subfraction distribution in the diabetes prevention program. Journal of Clinical Endocrinology and Metabolism, 98(10), 3989-3998. https://doi.org/10.1210/jc.2013-1452

[13] Hu, M., Ye, P., Liao, H., Chen, M., \& Yang, F. (2016). Metformin Protects H9C2 Cardiomyocytes from High-Glucose and Hypoxia/Reoxygenation Injury via Inhibition of Reactive Oxygen Species Generation and Inflammatory Responses: Role of AMPK and JNK. Journal of Diabetes Research, 2016. https://doi.org/10.1155/2016/2961954

[14] Huang, N. L., Chiang, S. H., Hsueh, C. H., Liang, Y. J., Chen, Y. J., \& Lai, L. P. (2009). Metformin inhibits TNF- $\alpha$-induced IкB kinase phosphorylation, IאB- $\alpha$ degradation and IL-6 production in endothelial cells through PI3K-dependent AMPK phosphorylation. International Journal of Cardiology, 134(2), 169-175. https://doi.org/10.1016/j.ijcard.2008.04.010

[15] Jadeja, R. N., Thounaojam, M. C., Patel, D. K., Devkar, R. V., \& Ramachandran, A. V. (2010). Pomegranate (Punica granatum L.) juice supplementation attenuates isoproterenol-induced cardiac necrosis in rats. Cardiovascular Toxicology, 10(3), 174-180. https://doi.org/10.1007/s12012-010-9076-9

[16] Jadhav, S., Ferrell, W., Greer, I. A., Petrie, J. R., Cobbe, S. M., \& Sattar, N. (2006). Effects of Metformin on Microvascular Function and Exercise Tolerance in Women With Angina and Normal Coronary Arteries. A Randomized, Double-Blind, PlaceboControlled Study. Journal of the American College of Cardiology, 48(5), 956-963. https://doi.org/10.1016/j.jacc.2006.04.088

[17] Kewalramani, G., Puthanveetil, P., Wang, F., Kim, M. S., Deppe, S., Abrahani, A., ... Rodrigues, B. (2009). AMP-activated protein kinase confers protection against TNF- $\alpha$-induced cardiac cell death. Cardiovascular Research, 84(1), 42-53. https://doi.org/10.1093/cvr/cvp166

[18] Kirpichnikov, D., McFarlane, S. I., \& Sowers, J. R. (2002, July 2). Metformin: An update. Annals of Internal Medicine. American College of Physicians. https://doi.org/10.7326/0003-4819-137-1-200207020-00009

[19] Lalu, M. M., Pasini, E., Schulze, C. J., Ferrari-Vivaldi, M., Ferrari-Vivaldi, G., Bachetti, T., \& Schulz, R. (2005). Ischaemiareperfusion injury activates matrix metalloproteinases in the human heart. European Heart Journal, 26(1), 27-35. https://doi.org/10.1093/eurheartj/ehi007

[20] Lexis, C. P. H., Van Der Horst, I. C. C., \& Lipsic, E. (2012, November). Effects of metformin on insulin resistance in heart failure. Which came first: The chicken or the egg? European Journal of Heart Failure. https://doi.org/10.1093/eurjhf/hfs 155

[21] Lexis, C. P. H., Wieringa, W. G., Hiemstra, B., Van Deursen, V. M., Lipsic, E., Van Der Harst, P., ... Van Der Horst, I. C. C. (2014). Chronic metformin treatment is associated with reduced myocardial infarct size in diabetic patients with ST-segment elevation myocardial infarction. Cardiovascular Drugs and Therapy, 28(2), 163-171. https://doi.org/10.1007/s10557-013-6504-7

[22] Li, L., Mamputu, J. C., Wiernsperger, N., \& Renier, G. (2005). Signaling pathways involved in human vascular smooth muscle cell proliferation and matrix metalloproteinase-2 expression induced by leptin: Inhibitory effect of metformin. Diabetes, 54(7), 2227-2234. https://doi.org/10.2337/diabetes.54.7.2227

Al-Qaisy, Y., Arif, I. and Al-Ezzi, M., 2021. New Perceptions in the Cardioprotective Effect of Metformin Against Isoproterenol Induced Cardiotoxicity in Male Rats. Journal port Science Research, 4(1), pp.27-34. https://doi.org/10.36371/port.2021.6 
[23] Lu, J., Ji, J., Meng, H., Wang, D., Jiang, B., Liu, L., ... Meng, Q. H. (2013). The protective effect and underlying mechanism of metformin on neointima formation in fructose-induced insulin resistant rats. Cardiovascular Diabetology, 12(1). https://doi.org/10.1186/1475-2840-12-58

[24] Mamputu, J. C., Wiernsperger, N. F., \& Renier, G. (2003). Antiatherogenic properties of metformin: The experimental evidence. Diabetes and Metabolism. Elsevier Masson SAS. https://doi.org/10.1016/s1262-3636(03)72790-6

[25] Miura, S., Ohno, I., Suzuki, J., Suzuki, K., Okada, S., Okuyama, A., ... Shirato, K. (2003). Inhibition of matrix metalloproteinases prevents cardiac hypertrophy induced by $\beta$-adrenergic stimulation in rats. Journal of Cardiovascular Pharmacology, 42(2), 174 181. https://doi.org/10.1097/00005344-200308000-00004

[26] Morrow, V. A., Foufelle, F., Connell, J. M. C., Petrie, J. R., Gould, G. W., \& Salt, I. P. (2003). Direct activation of AMP-activated protein kinase stimulates nitric-oxide synthesis in human aortic endothelial cells. Journal of Biological Chemistry, 278(34), 31629-31639. https://doi.org/10.1074/jbc.M212831200

[27] Musi, N., Hirshman, M. F., Nygren, J., Svanfeldt, M., Bavenholm, P., Rooyackers, O., ... Goodyear, L. J. (2002). Metformin increases AMP-activated protein-kinase activity in skeletal muscle of subjects with type 2 diabetes. Diabetes, 51(7), 2074-2081. https://doi.org/10.2337/diabetes.51.7.2074

[28] Peng, W., Zhang, Y., Zhu, W., Cao, C. M., \& Xiao, R. P. (2009, October). AMPK and TNF- $\alpha$ at the crossroad of cell survival and death in ischaemic heart. Cardiovascular Research. https://doi.org/10.1093/cvr/cvp272

[29] Sachidanandam, K., Hutchinson, J. R., Elgebaly, M. M., Mezzetti, E. M., Dorrance, A. M., Motamed, K., \& Ergul, A. (2009). Glycemic control prevents microvascular remodeling and increased tone in Type 2 diabetes: Link to endothelin-1. American Journal of Physiology - Regulatory Integrative and Comparative Physiology, 296(4). https://doi.org/10.1152/ajpregu.90537.2008

[30] Timmers, L., Pasterkamp, G., De Hoog, V. C., Arslan, F., Appelman, Y., \& De Kleijn, D. P. V. (2012, May 1). The innate immune response in reperfused myocardium. Cardiovascular Research. https://doi.org/10.1093/cvr/cvs018

[31] Soraya, H., Clanachan, A. S., Rameshrad, M., Maleki-Dizaji, N., Ghazi-Khansari, M., \& Garjani, A. (2014). Chronic treatment with metformin suppresses toll-like receptor 4 signaling and attenuates left ventricular dysfunction following myocardial infarction. European Journal of Pharmacology, 737, 77-84. https://doi.org/10.1016/j.ejphar.2014.05.003

[32] Soraya, H., Farajnia, S., Khani, S., Rameshrad, M., Khorrami, A., Banani, A., ... Garjani, A. (2012). Short-term treatment with metformin suppresses toll like receptors (TLRs) activity in isoproterenol-induced myocardial infarction in rat: Are AMPK and TLRs connected? International Immunopharmacology, 14(4), 785-791. https://doi.org/10.1016/j.intimp.2012.10.014

[33] Vassiliadis, E., Barascuk, N., Didangelos, A., \& Karsdal, M. A. (2012). Novel cardiac-specific biomarkers and the cardiovascular continuum. Biomarker Insights. Libertas Academica Ltd. https://doi.org/10.4137/BMI.S9536

[34] Wang, X. F., Zhang, J. Y., Li, L., Zhao, X. Y., Tao, H. L., \& Zhang, L. (2011). Metformin improves cardiac function in rats via activation of AMP-activated protein kinase. Clinical and Experimental Pharmacology and Physiology, 38(2), 94-101. https://doi.org/10.1111/j.1440-1681.2010.05470.x

[35] Yin, M., van der Horst, I. C. C., van Melle, J. P., Qian, C., van Gilst, W. H., Silljé, H. H. W., \& de Boer, R. A. (2011). Metformin improves cardiac function in a nondiabetic rat model of post-MI heart failure. American Journal of Physiology - Heart and Circulatory Physiology, 301(2). https://doi.org/10.1152/ajpheart.00054.2011

[36] Zhang, T., Hu, X., Cai, Y., Yi, B., \& Wen, Z. (2014). Metformin protects against hyperglycemia-induced cardiomyocytes injury by inhibiting the expressions of receptor for advanced glycation end products and high mobility group box 1 protein. Molecular Biology Reports, 4l(3), 1335-1340. https://doi.org/10.1007/s11033-013-2979-3

[37] Zhuo, X. Z., Wu, Y., Ni, Y. J., Liu, J. H., Gong, M., Wang, X. H., .. Song, P. (2013). Isoproterenol instigates cardiomyocyte apoptosis and heart failure via AMPK inactivation-mediated endoplasmic reticulum stress. Apoptosis, 18(7), 800-810. https://doi.org/10.1007/s10495-013-0843-5 